\title{
Synthesis and Characterization of Tetraaza Macrocyclic Nickel(II) and Copper(II) Complexes Bearing Two Tetrazole Pendant Arms
}

\author{
Shin-Geol Kang," Hyunja Kim, Nahee Kim, and Jong Hwa Jeong ${ }^{\dagger}$ \\ Deparment of Chemistry, Daegu Chiversity, Gyeongsan 712-714. Korea. E-mail: sgkangâdaeguac.kr \\ Department of Chemistry, Kungpook National Lniversitv, Daegu 702-701, Korea \\ Received September 21, 2009. Accepted October 16, 2009
}

Key Words: Macrocyclic complex. Tetrazole. Functional pendant arms. Nickel(II) complex. X-Ray structure

Organic and inorganic compounds containing tetrazole group(s) have received considerable attention because of their potential applications in various fields, such as medicine, explosive, materials sciences. photography, and sweetener. ${ }^{1.7}$ Various types of substituted tetrazoles have been prepared from the reaction of organic nitriles $(\mathrm{R}-\mathrm{CN})$ with azide $\left(\mathrm{N}_{3}{ }^{-}\right)$ion in the presence of a transition metal ion. It has been suggested that the reaction of coordinated R-CN with free $\mathrm{N}_{3}^{-}$ion would produce the tetrazolato complex Ia. while Ib as well as Ia could be prepared from the reaction of coordinated $\mathrm{N}_{3}{ }^{-}$with free $\mathrm{R}-\mathrm{CN}$ (Scheme 1), ${ }^{6,7}$ is well known that the cyclization reaction is catalyzed by the metal ion. In the presence of an acid the tetrazolato complexes Ia and $\mathbf{I b}$ are readily decomposed to produce the metal-free tetrazoles IIa and $\mathbf{I l b}$. respectively. Therefore. coordination behaviors of neutral tetrazoles are not thoroughly investigated.

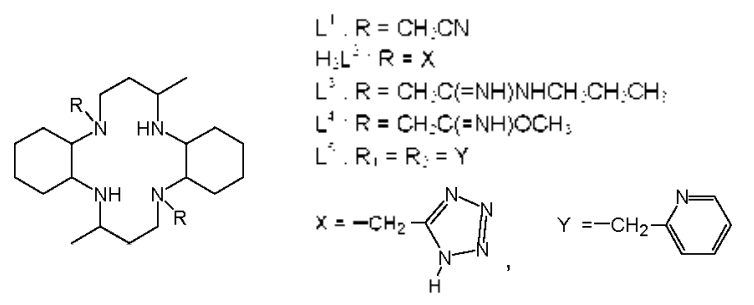

There has been continuing interest in the synthesis of polyaza macrocyclic compounds bearing various ty'pes of functional pendant arms, since chemical properties of such compounds

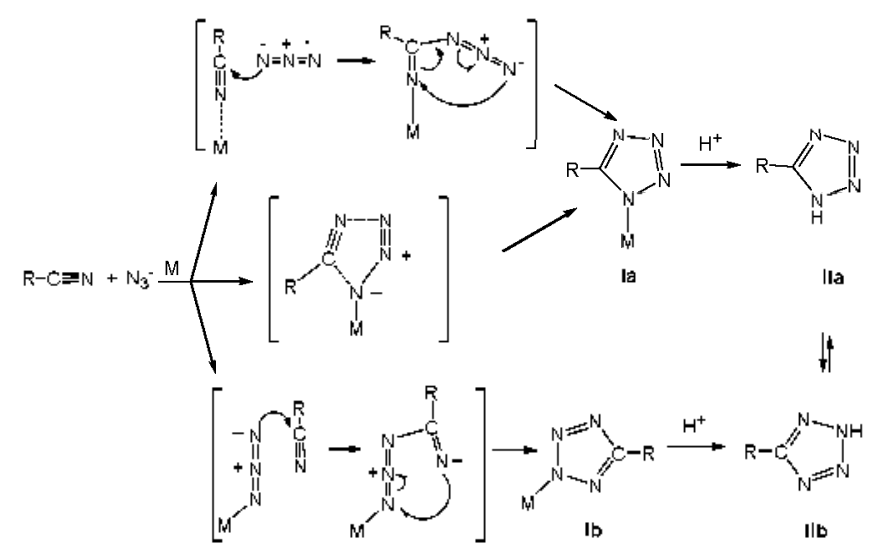

Scheme 1 are influenced by the nature of the functional groups. ${ }^{8-15}$ In this work, we examined the reaction of $\mathrm{N}_{3}{ }^{-}$with the $\mathrm{N}-\mathrm{CH}_{2} \mathrm{CN}$ pendant arms of $\left[\mathrm{NiL}^{1}\right]^{2-}$ and $\left[\mathrm{CuL}^{1}\right]^{2-}$ and successfully prepared $\left[\mathrm{Ni}\left(\mathrm{H}_{2} \mathrm{~L}^{2}\right)\right]^{\hat{O}^{-}}$and $\left[\mathrm{Cu}\left(\mathrm{H}_{2} \mathrm{~L}^{2}\right)\right]^{\hat{\beta}^{-}}$bearing two coordinated tetrazole pendant arnis. The tetrazolato complexes $\left[\mathrm{NiL}^{-}\right]$and $\left[\mathrm{CuL}^{-}\right]$ were also prepared. Herein, we report the sy nthesis, characterization. and chemical properties of the new functionalized macrocyclic nickel(II) and copper(II) complexes. along with the crystal structure of $\left[\mathrm{Ni}\left(\mathrm{H}_{2} \mathrm{~L}^{2}\right)\right]\left(\mathrm{ClO}_{4}\right)_{2}$.

\section{Expelimental}

Measurements. Infrared spectra were recorded using a Shimadzu IR-4+40 spectrophotometer. electronic absorption spectra with an Analytikjena Specord 200 UV/Vis spectrophotometer. and conductance measurements with a Metrolum Herisau Conductometer E518. Elemental analyses were performed at the Research Center for Instrumental Analy sis. Daegu Univerșity. Gyeongsan, Korea. FAB mass spectra were performed at the Korea Basic Science Institute. Daegu Korea. Magnetic moments were calculated from magnetic susceptibility data obtained at $20^{\circ} \mathrm{C}$ using a Johnson Matthey MK-l magnetic susceptibiliț balance.

Preparation of $\left[\mathrm{Ni}\left(\mathrm{H}_{2} \mathrm{~L}^{2}\right)\right]\left(\mathrm{ClO}_{4}\right)_{2} \cdot 2 \mathrm{CH}_{3} \mathrm{SOCH}_{3}$ (1). Caution! Perchlorate salts of metal complexes with organic ligands are often explosive and should be handled with great caution! To a warm acetonitrile suspension $(20 \mathrm{~mL})$ of $\left[\mathrm{NiL}^{\mathrm{j}}\right]\left(\mathrm{ClO}_{4}\right)_{2}^{13}(1.0 \mathrm{~g}$. $1.5 \mathrm{mmol}$ ) was added $\mathrm{NaN}_{3}(1.5 \mathrm{~g} .23 \mathrm{~mm}$ ol $)$. The mixture was stirred in a hot water bath $\left(60 \sim 70^{\circ} \mathrm{C}\right)$ for $\mathrm{ca}$. $10 \mathrm{~min}$. During this time the orange-red solid went to the solution. and then a purple solid was precipitated. After the addition of concentrated $\mathrm{HClO}_{4}(c a .1 .5 \mathrm{~mL})$ dissolved in water $(20 \mathrm{~mL})$. the resulting solution was stored in a refrigerator for $>5 \mathrm{~h}$ to precipitate a pale purple solid. The solid was filtered. washed with methanol. and dried in air. The crude product was recrystallized from hot DMSO solution containing $3-5$ drops of concentrated $\mathrm{HClO}_{4}$. Yield: $\sim 80 \%$. Anal Found: C. 36.79: H. 6.48: N, 18.73. Calc. for $\mathrm{C}_{2} \mathrm{H}_{56} \mathrm{Cl}_{2} \mathrm{~N}_{1} \mathrm{NiO}_{1 \mathrm{i}} \mathrm{S}_{2}: \mathrm{C}, 36.77 ; \mathrm{H}, 6.17 ; \mathrm{N} .18 .38 \%$. IR $\left(\mathrm{cm}^{-1}\right): 3250[\mathrm{v}(\mathrm{N}-\mathrm{H})] .3117[\mathrm{v}(\mathrm{N}-\mathrm{H})] .1655$ (tetrazole). 1570 (tetrazole). and $1100\left(\mathrm{br}, \mathrm{ClO}_{4}^{-}\right)$. $\mu_{\mathrm{eff}}=2.88 \mu_{\mathrm{B}}$ at $20^{\circ} \mathrm{C}$.

Preparation of $\left[\mathrm{NiL}^{2}\right]$ (2). The addition of triethylamine $(0.3$ $\mathrm{mL}$ ) or $1.0 \mathrm{M} \mathrm{NaOH}$ aqueous solution $(20 \mathrm{~mL})$ to a warm DMSO solution ( $c a .20 \mathrm{~mL}$ ) of $1(0.5 \mathrm{~g}, 0.7 \mathrm{~nm}$ nol) produces a pale purple solid. The product was filtered, washed with water. and dried in air. Yield: $\rightarrow 90 \%$. Anal. Found: C, 51.32; H. 8.01; N. 30.60 . 
Calc. for $\mathrm{C}_{24} \mathrm{H}_{42} \mathrm{Cl}_{2} \mathrm{~N}_{12} \mathrm{Ni}: \mathrm{C}, 51.72 ; \mathrm{H}, 7.60 ; \mathrm{N}, 30.16 \%$. IR $\left(\mathrm{cm}^{-1}\right): 3261[\mathrm{v}(\mathrm{N}-\mathrm{H})] .1655$ (tetrazole) 1585 (tetrazole), and $1100\left(\right.$ br. $\left.\mathrm{ClO}_{+}^{-}\right) \cdot \mu_{\mathrm{etf}}=2.86 \mu_{\mathrm{B}}$ at $20^{\circ} \mathrm{C}$.

Preparation of $\left[\mathrm{Cu}\left(\mathrm{H}_{2} \mathrm{~L}^{2}\right)\right]\left(\mathrm{ClO}_{4}\right)_{2} \cdot 2 \mathrm{CH}_{3} \mathrm{SOCH}_{3}(3)$. An acetonitrile suspension $(30 \mathrm{~mL})$ of $\left.\left[\mathrm{CuL}^{1}\right]\left(\mathrm{ClO}_{4}\right)_{2}\right]^{3}(1.0 \mathrm{~g} .1 .5$ mmol) and $\mathrm{NaN}_{3}(1.5 \mathrm{~g}, 23 \mathrm{mmol}$ ) was refluxed for $>28 \mathrm{~h}$ and then cooled to room temperature. After the addition of $1.0 \mathrm{M}$ $\mathrm{HClO}_{4}$ aqueous solution ( $c$ a. $20 \mathrm{~mL}$ ). the resulting solution was evaporated at room temperature to precipitate a blue-purple solid. The product was collected by filtration. washed with methanol, and dried in air. It was recry stallized by the addition of $0.1 \mathrm{M} \mathrm{HClO}_{4}$ aqueous solution to a warm DMSO solution of the crude product. Yield: $\sim 60 \%$. Anal. Found: C. $36.31 ; \mathrm{H}$. 6.63: N. 18.34. Calc. for $\mathrm{C}_{28} \mathrm{H}_{36} \mathrm{Cl}_{2} \mathrm{~N}_{12} \mathrm{NiO}_{10} \mathrm{~S}: \mathrm{C}, 36.58: \mathrm{H}$. 6.14: N. $18.28 \%$. FAB mass $(m / z): 662.2$ for $\left[\mathrm{Cu}\left(\mathrm{H}_{2} \mathrm{~L}^{2}\right)+\mathrm{ClO}_{4}\right]^{-}$. 562.2 for $\left[\mathrm{Cu}\left(\mathrm{H}_{2} \mathrm{~L}^{2}\right)-\mathrm{H}\right]^{-}$. IR $\left(\mathrm{cm}^{-1}\right): 3229[\mathrm{v}(\mathrm{N}-\mathrm{H})], 3151$ [v(N-H)], 1640 (tetrazole), and 1575 (tetrazole).

Preparation of $\left[\mathbf{C u L}^{2}\right]$ (4). To a DMSO solution ( $20 \mathrm{~mL}$ ) of 3 $(0.5 \mathrm{~g} .0 .7 \mathrm{mmol})$ was added triethy lamine $(0.1 \mathrm{~mL})$. The pale blue solution was slowly evaporated at room temperature to produce a pale blue solid. The product was collected by filtration, washed with methanol. and dried in air. Y1eld: $\sim 80 \%$. And. Found: C. 50.79; H. 7.93: N, 29.43. Calc. for $\mathrm{C}_{24} \mathrm{H}_{42} \mathrm{~N}_{3} \mathrm{Cu}$ : C. 51.27: H. 7.53: N. $29.29 \%$. IR $\left(\mathrm{cm}^{-1}\right): 3218[v(\mathrm{~N}-\mathrm{H})]$, and 1655 (tetrazole). and 1570 (tetrazole)

Crystal stmicture analysis. Single cry'stals of 1 suitable for the $\mathrm{X}$-ray crystallography were obtained from warm DMSO solution containing $3 \sim 5$ drops of concentrated $\mathrm{HClO}_{4}$. Intensity data were collected with $\mathrm{CAD}+$ diffractometer using Mo-K $\alpha$ radiation $(\lambda=0.71073 \mathrm{~A})$. Absorption corrections were applied with $3 y$ scans. The structures were solved by direct methods and refined by full-matrix least-squares methods based on $\mathrm{F}^{2}$ using SHEL XS-97 and SHELXL-97. ${ }^{16}$ Non-hydrogen atoms were refined anisotropically and all hydrogen atoms were included in calculated positions.

Crystal and refinement data: $\mathrm{C}_{2 \Sigma} \mathrm{H}_{56} \mathrm{Cl}_{2} \mathrm{~N}_{12} \mathrm{NiO}_{10} \mathrm{~S}_{3} . \mathrm{H}=$ 914.55, Monoclinic, $P 2{ }_{1} / c, a=8.38+1(3), b=15.3563(6), c=$ $15.4446(6) \AA, \beta=102.798(1)^{\circ}, \mathrm{I}=1939.1(2) \AA^{3}, Z=4, D_{\text {calc }}=$ $1.566 \mathrm{~g} \mathrm{~cm}^{-3}, t=8.16 \mathrm{~cm}^{-1}$. Theta range $=1.89 \sim 28.30^{\circ} .-11 \leq$ $h \leq 10,-17 \leq k \leq 19 .-16 \leq 1 \leq 19$, GOF on $F^{2}=1.097$, Final $R_{1}=0.0334 . w R_{2}=0.0822(I>2 \sigma(I)) . R_{1}=0.0370 . w R_{2}=0.0840$ (all data), Largest diff. Peak and hole $=0.424$ and $-0.417 \mathrm{eA}^{\cdot 3}$.

\section{Results and Discussion}

Synthesis. As described in the Experimental section. the nickel(II) complex 1 bearing two tetrazole pendant anns was prepared readily by the reaction of $\left[\mathrm{NiL}^{\mathrm{l}}\right]\left(\mathrm{ClO}_{4}\right)_{2}$ with $\mathrm{NaN}_{3}$. The reaction was found to be completed within 10 min at 60 $70^{\circ} \mathrm{C}$. The copper(II) complex 3 bearing two tetrazole pendant arms was also prepared by the reaction of $\left[\mathrm{CuL}^{-}\right]\left(\mathrm{ClO}_{4}\right)=$ with $\mathrm{NaN}_{3}$. However. the preparation of the copper(II) complex requires much longer reaction time ( $>24 \mathrm{~h}$ ) under similar conditions. indicating that the reaction is strongly influenced by the nature of the central metal ion. This also supports the suggestion that the reaction of $\mathrm{NaN}_{3}$ with the $\mathrm{N}-\mathrm{CH}_{2} \mathrm{CN}$ groups in [ $\mathrm{NiL}^{1}$ ] $\left(\mathrm{ClO}_{4}\right)_{2}$ or $\left[\mathrm{CLL}^{\dagger}\right]\left(\mathrm{ClO}_{4}\right)_{2}$ may be initiated by the formation of trans-octahedral species as an intermediate, in which $\mathrm{N}_{3}{ }^{-}$ions and/or the pendant nitrile groups are coordinated to the central metal ion. The slower reaction of the copper(II) complex, compared to that of the nickel(II) complex. can be attributed to the relatively weak axial $\mathrm{Cu}-\mathrm{N}_{3}$ (or $\mathrm{Cu}$-nitrile group) interaction of the trans-octahedral intermediate caused by the Jahn-Teller distortion.

The addition of a base to DMSO solution of 1 or 3 produces 2 or 4 where the pendant five-menbered rings are deprotonated (Eq.(1)).

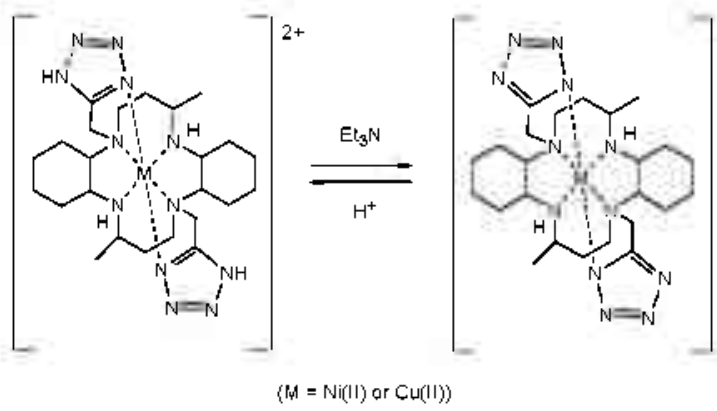

Crystal Structure of 1. A perspective view of the cation of 1 is given in Fig. 1. Two tetrazole pendant arms are coordinated to the metal ion through the nitrogen atoms $\left(\mathrm{N}(3)\right.$ and $\left.\mathrm{N}\left(3^{\text {ï}}\right)\right)$. and the complex has distorted rans-octahedral coordination geometry with an inversion center. The cyclohexane rings and

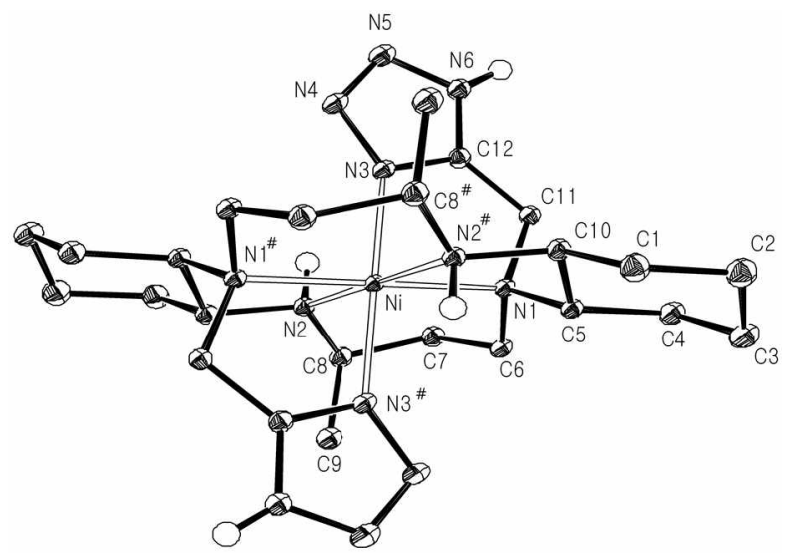

Figure 1. A view of $\left[\mathrm{Ni}_{1}\left(\mathrm{H}_{2} \mathrm{~L}^{2}\right)\right]^{2-}$ in 1 . $\mathrm{H}$ atoms attached to the carbon atoms are omitted for clarity.

Table 1. Selected Bond Distances $[\AA]$ and Angles [ $]$ for 1

\begin{tabular}{lrlr}
\hline $\mathrm{Ni}(1)-\mathrm{N}(1)$ & $2.136(2)$ & $\mathrm{Ni}(1) \mathrm{N}(2)$ & $2.100(2)$ \\
$\mathrm{Ni}(1) \mathrm{N}(3)$ & $2.122(2)$ & $\mathrm{C}(6)-\mathrm{N}(1)$ & $1.497(2)$ \\
$\mathrm{C}(11) \mathrm{N}(1)$ & $1.496(2)$ & $\mathrm{C}(12) \mathrm{N}(3)$ & $1.313(2)$ \\
$\mathrm{C}(12)-\mathrm{N}(6)$ & $1.324(2)$ & $\mathrm{N}(3)-\mathrm{N}(4)$ & $1.366(3)$ \\
$\mathrm{N}(4)-\mathrm{N}(5)$ & $1.292(2)$ & $\mathrm{N}(5)-\mathrm{N}(6)$ & $1.350(2)$ \\
\hline $\mathrm{N}(1)-\mathrm{Ni}-\mathrm{N}\left(1^{*}\right)$ & $180.0(1)$ & $\mathrm{N}(1)-\mathrm{Ni}-\mathrm{N}(2)$ & $96.3(1)$ \\
$\mathrm{N}(1)-\mathrm{Ni}-\mathrm{N}(3)$ & $80.0(1)$ & $\mathrm{N}(2)-\mathrm{Ni}-\mathrm{N}(3)$ & $85.3(1)$ \\
$\mathrm{Ni}-\mathrm{N}(3) \mathrm{N}(4)$ & $140.1(2)$ & $\mathrm{Ni}-\mathrm{N}(3) \mathrm{C}(12)$ & $113.3(2)$ \\
$\mathrm{N}(4)-\mathrm{N}(5) \mathrm{N}(6)$ & $107.3(2)$ & $\mathrm{N}\left(2^{*}\right)-\mathrm{Ni}-\mathrm{N}(3)$ & $94.7(2)$ \\
$\mathrm{C}(12)-\mathrm{N}(3)-\mathrm{N}(4)$ & $106.6(2)$ & $\mathrm{C}(12)-\mathrm{N}(6) \mathrm{N}(5)$ & $108.2(2)$ \\
$\mathrm{N}(3)-\mathrm{N}(4)-\mathrm{N}(5)$ & $109.3(3)$ & $\mathrm{N}(3)-\mathrm{C}(12)-\mathrm{N}(6)$ & $108.7(3)$ \\
$\mathrm{N}(3)-\mathrm{C}(12)-\mathrm{C}(11)$ & $123.4(2)$ & & \\
\hline
\end{tabular}


Table 2. Electronic Absortion Spectral Data for the Complexes

\begin{tabular}{|c|c|c|}
\hline Complex & \multicolumn{2}{|c|}{$\lambda_{\pi \mathrm{Tl} \alpha}, \mathrm{nm}\left(\varepsilon, \mathrm{M}^{-1} \mathrm{~cm}^{-1}\right)^{a r}$} \\
\hline 1 & $520(4.7)$ & $790(4.1)$ \\
\hline 2 & $520^{b}$ & \\
\hline$\left[\mathrm{NiL}^{3}\right]\left(\mathrm{ClO}_{4}\right)_{2}{ }^{\mathrm{c}}$ & $510(8)^{4}$ & $800(7.5)^{d}$ \\
\hline$\left[\mathrm{NiL}^{-1}\right]\left(\mathrm{ClO}_{4}\right)_{2}{ }^{e}$ & $513(12)$ & $800(5.5)$ \\
\hline$\left.\left[\mathrm{NiL}^{4}\right]\left(\mathrm{ClO}_{4}\right)\right)^{f}$ & $530(6.0)$ & \\
\hline 3 & $570(105)$ & $580^{b}$ \\
\hline 4 & $584^{5}$ & \\
\hline$\left[\mathrm{CuL}^{+}\right]\left(\mathrm{ClO}_{4}\right)_{2}{ }^{e}$ & $587(65)^{g}$ & \\
\hline
\end{tabular}

"Measured in DMSO at room temperature unless otherwise specified. "Measured in Nujol mull. ${ }^{\circ}$ Ref. $14 .{ }^{\prime \prime}$ Measured in water. ${ }^{\circ}$ Ref. $13 .{ }^{\prime}$ Ref. $15 .{ }^{8}$ Measured in nitromethane.

the sii-membered chelate rings adopt chair conformations. The tetrazole and methyl groups in each six-membered chelate ring are anti with respect to the $\mathrm{NiN}_{4}$ plane

Selected bond distances and angles of $\mathbf{1}$ are listed in Table 1 . The $\mathrm{C}(12)-\mathrm{N}(3)$ bond distance $[1.313(2) \dot{A}]$ is shorter than the $\mathrm{C}(12)-\mathrm{N}(6)$ distance $[1.32+(2) \AA]$ and is corresponding to the $\mathrm{C}=\mathrm{N}$ double bond. The $\mathrm{N}(4)-\mathrm{N}(5)$ double bond distance [1.292 (2) $\dot{A}$ ] is distinctly shorter than the $\mathrm{N}(3)-\mathrm{N}(4)$ and $\mathrm{N}(5)-\mathrm{N}(6)$ distances $[1.366(3)$ or $1.350(2) \AA]$. The N(3) atom is located at the trigonal plane of the Ni. C(12), and N(3) atoms. The axial $\mathrm{Ni}-\mathrm{N}$ (3) bond is not perpendicular to the in-plane $\mathrm{Ni}-\mathrm{N}$ bonds. The Ni-N distances [2.100(2) - 2.136(2) A] are typical for highspin trans-octahedral nickel(II) complexes with 14-membered tetraaza macrocyclic ligands. ${ }^{13-15}$ Although the axial Ni-N(3) (pendant arm) distance $[2.122(2) \dot{A}]$ is longer than the in-plane $\mathrm{Ni}-\mathrm{N}(2)$ (secondary) distance [2.100(2) $\AA$ ]. it is $c a .0 .01 \AA$ shorter than the in-plane $\mathrm{Ni}-\mathrm{N}(1)$ (tertiary) distance [2.136(2) A]. It is also seen that the $\mathrm{Ni}-\mathrm{N}(3)$ distance is ca. $0.13 \AA$ shorter than the avial Ni-N (pyridine) distance $(2.255(4) \AA)$ of $\left[\mathrm{NiL}^{5}\right] \mathrm{Cl}_{2}{ }^{15}$ This clearly shows that the five-membered tetrazole pendant arms in 1 bind the metal ion more strongly than the pyridine groups in $\left[\mathrm{NiL}^{5}\right] \mathrm{Cl}_{2}$. However, the coordination ability of the tetrazole group is weaker than that of the imidate ester or amidine pendent arm in $\left[\mathrm{NiL}^{3}\right]\left(\mathrm{ClO}_{4}\right)_{2}$ or $\left[\mathrm{NiL}^{4}\right]\left(\mathrm{ClO}_{4}\right)_{2}$ : the $\mathrm{Ni}-\mathrm{N}(3)$ distance is considerably longer than the axial $\mathrm{Ni}-\mathrm{N}$ distance of $\left[\mathrm{NiL}^{3}\right]\left(\mathrm{ClO}_{4}\right)_{2}[2.088(3) \AA]$ or $\left[\mathrm{NiL}^{4}\right]\left(\mathrm{ClO}_{4}\right)=[2.100(3) \AA]^{13.14}$

Spectra and Properties. Both $\mathbf{1}$ and $\mathbf{3}$ dissolve in DMSO, but are nearly insoluble in acetonitrile. nitromethane. or water. The tetrazole groups of complexes are not protonated even in $3.0 \mathrm{M} \mathrm{HClO}_{4}$ solutions. As described above. however they readily undergo deprotonation in basic solutions to give the neutral complex 2 or 4

The value of magnetic moment of $1\left(2.88 \mu_{\mathrm{B}}\right)$ or $2\left(2.86 \mu_{\mathrm{B}}\right)$ is consistent with a $\mathrm{d}^{8}$ electronic configuration in octahedral coordination geometry. The infrared spectnum of 1 shows $v$ $(\mathrm{N}-\mathrm{H})$ of the secondary amino groups at 3250 and $3117 \mathrm{~cm}^{-1}$. Peaks corresponding to the tetrazole groups are also observed at 1655 and $1570 \mathrm{~cm}^{-1}$. A broad band arising from the presence of perchlorate anions is observed at $1100 \mathrm{~cm}^{-1}$. The spectrum of 3 is quite similar to that of the corresponding the nickel(II) complex. The electronic absorption spectrum (Table 2) of $\mathbf{1}$ is not quite different from those of the nickel(II) complexes with
$\mathrm{L}^{3} . \mathrm{L}^{4}$. and $\mathrm{L}^{5}{ }^{13-15}$ However. the wavelength $(520 \mathrm{~nm})$ for 1 is ca. $10 \mathrm{~nm}$ longer and shorter than those for $\left[\mathrm{NiL}^{3}\right]\left(\mathrm{ClO}_{4}\right)_{2}$ and $\left[\mathrm{NiL}^{5}\right]\left(\mathrm{ClO}_{4}\right)_{2}$. respectively. This trend may be related to the axial $\mathrm{Ni}-\mathrm{N}$ bond distances of the complexes $\left(\left[\mathrm{NiL}^{3}\right]\left(\mathrm{ClO}_{4}\right)_{2}<\right.$ $\left.\mathbf{1}<\left[\mathrm{NiL}^{5}\right]\left(\mathrm{ClO}_{4}\right)_{2}\right)$. The spectnum of $\mathbf{3}$ measured in DMSO shows a d-d transition band at $570 \mathrm{~nm}\left(\varepsilon=105 \mathrm{M}^{1} \mathrm{~cm}^{-1}\right)$. which is also comparable with those of $\left[\mathrm{CuL}^{+}\right]\left(\mathrm{ClO}_{4}\right)_{2}$ and other related trans-octahedral copper(II) conplexes. ${ }^{1-15}$ The value of the molar conductance for $1\left(58 \Omega^{-1} \mathrm{~cm}^{2} \mathrm{~mol}^{-1}\right)$ or $3\left(59 \Omega^{-1} \mathrm{~cm}^{2} \mathrm{~mol}^{-1}\right)$ in DMSO indicates that each complex is a $1: 2$ electrolyte. ${ }^{1 \text { " }}$

The neutral complexes 2 and $t$ are nearly insoluble even in DMSO. unlike 1 or 3 . The infrared spectra of $\mathbf{2}$ and $\mathbf{4}$ show $v$ $(\mathrm{N}-\mathrm{H})$ of the secondary amino groups at 3261 and $3218 \mathrm{~cm}^{-1}$. respectively: no peak assignable to perchlorate anion is observed. The electronic absorption spectra of $2(c a .520 \mathrm{~mm})$ and $\mathbf{4}(\mathrm{ca}$. $580 \mathrm{~nm}$ ) measured in Nujol mull are similar to those of 1 and 3. respectively, indicating that the pendant tetrazolato groups are also involved in coordination.

\section{Summan}

This work has shown that 1 and $\mathbf{3}$ bearing two coordinated tetrazole pendant arms can be prepared by the reaction of $\mathrm{N}_{3}{ }^{-}$ ion with $\left[\mathrm{NiL}^{1}\right]\left(\mathrm{ClO}_{4}\right)_{2}$ or $\left[\mathrm{CLL}^{3}\right]\left(\mathrm{ClO}_{4}\right)_{2}$. In the presence of a base. 1 and 3 are readily deprotonated to 2 or 4 . This work also shows that the coordination ability of the tetrazole group in $\mathbf{1}$ is stronger than the pendant pyridine group in $\left[\mathrm{NiL}^{5}\right] \mathrm{Cl}_{2}$. To the best of our knowledge, 1 and 3 are the first examples of 14-membered tetraaza macrocyclic complexes bearing two coordinated tetrazole pendant arms.

Supplementary Matelial. Crystallographic data of 1 are available from the Cambridge Structural Database (CCDC 748100). Copies of the data can be obtained free of charge, on application to CCDC. 12 Union Road. Cambridge CB2 EEZ. UK (http: //www.ccdc.cam ac.uk, fax: $+4+-1223-336-033$. or e-mail: depositaccdc.cam.ac.uk).

Aclonowledgments. This work was supported in part by the Research Grant of Daegu University.

\section{References}

1. (a) Mukhopadhyay, S.; Lasri, T.; Chamier, M. A. T.; Guedes da Silva, M. F. C.: Pombeiro, A. T. L. Dalton Trans. 2007, 5297; (b) He, X.; Yuan, D.-Q. horg. Chem. 2006, 45,5760 and references cited therein.

2. (a) Zhang, X.-M; Zhao, Y.-F,; Wu, H.-S.; Batten, S. R; Ng, S. W. Dalton Trons. 2006, 3170; (b) Wang, L.-Z.; Qu, Z.-R.; Zhao, H.: Wang. X.-S.: Xiong. R.-G.; Xue, Z.-L. Ihorg. Chem. 2003, +2, 3969 .

3. Kim, Y.-J:- Lee, S.-H.: Lee, S.-H.: Jeon, S. L.: Lim. M. S.: Lee. S. W. horg. Chim Acta 2005, 358,650

4. Xue, X.; Wang, X.-S.; Wang, L. -Z.; Xiong, R.-G.; Abrahams, B. F.; You, X-Z; Xul, Z-L.; Che, C.-M. Inoig. Chem 2002, H1, 6544

5 (a) Bhattacharya, S.: Vemula, P. K. J. Oig. Chem 2005, 70,9677; (b) Ek, F.; Manner, S.: Wistrand, L.-G.: Frejd, T. J. Oig. Chem. $\mathbf{2 0 0 4}, 69,1346$

6. Yu, Z.: Wang. X.; Feng, Y.; Zhong, X. Inong. Chem. Commu. 2004, 7, 492. 
7. (a) Himo, F; Demko, Z. P.; Noodleman, L.: Sharpless, K. B. J. Am. Chem. Soc. 2003, 125, 9983 ; (b) Denko, Z P.: Sharpless, K. B. J. Org. Chem. 2001, 66, 7945: (c) Himo, F.: Demko, Z. P.: Noodleman, L.; Sharpless, K. B. J. Am. Chem. Soc. 2002, 124, 12210 .

8. (a) Costamagna, I.: Ferrandi, G.: Matsuliro, B.: Vannpus-Vallette, M.: Canales, T.; Villagran, M.; Vargas, J.: Aguime, M. J. Coond. Chen. Rev 2000, 196, 125; (b) Wainwight, K. P. Coont. Chem. Rev. 1997, 166, 35 .

9. (a) Tei, L.: Blake, A. I.; Bencini, A.: Voltancoli, B.: Wilson, C:; Schröder, M. Inong (thim .tcta 2002, 337, 59; (b) Kang, S. -G.: Kim, S.-T Teong, J. H. Inorg. Chin. Acta 2002, 340, 187.

10. (a) Kang, S.-G.; Kweon, J. K.: Jeong, G. R.: Lee, U. Bull. Korean Chem. Soc. 2008, 29, 1905 ; (b) Kang, S.-G.; Kim, N.: Lee, R. E.; Teong, J. H. Bull. Korean Chem. Soc. 2007, 28, 178]

11. Kang, S.-G.: Kim, M. S.: Choi, J.-S.: Whang, D.; Kin, K. J. Chem.
Soc., Dalton Trans. 1995, 363.

12. Kang, S.-G.; Nam, K, Teong, J. H. Inorg. Chim Acta 2009, 362, 1083

13. Kang, S.-G.; Song, J.; Teong, J. H. Bull. Konew Chem. Soc. 2002, 23,824

14. Kang, S.-G.; Kweon, J. K., Teong, J. H. Bull Korean Chem. Soc. $2005,26,1861$

15. (a) Kang, S.-G.; Kim, S.-T.; Teong, T. H. Polvhedron 1998, 17, 3227; (b) Choi, K.-Y.; Chun, K.-M.; Suh, I.-H. Polyhedron 1999, 18.2811

16. Sheldrick. G. M. SHELLS-97, Program for the Solution of Cnustal Structure; University of Göttingen, Göttingen: Gemany, 1990; Sheldrick, G. M. SHELLZ-97, Progrant for Crustal Structure Refimement: University of Göttingen: Göttingen, Germany, 1997.

17. Kang, S.-G.: Tung, S.-K: Kim, M.-S.; Park, T-H.: Yoh, S.-D. Bull. Chem. Soc. Jph. 1993, 66, 972. 